\title{
A Computational Contribution to Analyse the Connection of an Independent Power Producer to the Grid
}

\author{
L. M. Peres ${ }^{1}$, M. L. R. Chaves $^{1}$, G. C. Guimarães ${ }^{1}$, F. A. M. Moura ${ }^{2}$ \\ ${ }^{1}$ Universidade Federal de Uberlândia - UFU \\ School of Electrical Engineering \\ Av. JoãoNaves de Ávila 2121, Uberlândia, MG, Brazil - CEP 38400-902 \\ e-mails: larissaa_mp@yahoo.com.br, lynce@ufu.br, gcaixetag@yahoo.com.br \\ ${ }^{2}$ Universidade Federal do Triângulo Mineiro - UFTM \\ Department of Electrical Engineering \\ Uberaba, MG, Brazil \\ e-mail: fabricio@eletrica.uftm.edu.br
}

\begin{abstract}
The main objective of this paper is to present the modelling and performance of a synchronous generator connected to a distribution system to study the impacts of the expansion of distributed generation. Computer models for synchronous machine and its speed governor and voltage regulator were developed in the Alternative Transients Program (ATP) in its interface called ATPDraw. The implementation of such modelling has been developed in order to meet the requirements of companies in the energy sector, as well as to make a visual interface of easy understanding. To validate these modelling, some performance studies are realized for the synchronous generator of an Independent Power Producer (IPP) connected to the distribution system. The roles played by the speed governor and voltage regulator are highlighted when a severe contingency such as a three phase short-circuit occurs in the system.
\end{abstract}

\section{Keywords}

ATP/ATPDraw, distributed generation, power quality, renewable energy, synchronous generator.

\section{Nomenclature}

$J_{m} \quad$ Mechanical moment of inertia $\left(\mathrm{kg} \mathrm{m}^{2}\right)$,

$\theta_{\mathrm{m}} \quad$ Mechanical angle (rad),

$\mathrm{H} \quad$ Inertia constant (s),

$\mathrm{E}_{\mathrm{c}} \quad$ Kinetic energy $(\mathrm{J})$,

$\omega_{\mathrm{m}} \quad$ Mechanical angular velocity $(\mathrm{rad} / \mathrm{s})$,

$\mathrm{D}_{\mathrm{m}} \quad$ Mechanical damping coefficient,

Ta Accelerating torque (N.m),

$\mathrm{T}_{\mathrm{m}} \quad$ Mechanical torque (N.m),

$\mathrm{T}_{\mathrm{e}} \quad$ Electrical torque (N.m),

$\mathrm{V}$ Terminal voltage of independent generator (pu),

$\mathrm{V}_{\text {ref }} \quad$ Reference voltage (pu),

$\mathrm{K}_{\mathrm{a}} \quad$ Regulator amplifier gain,

$\mathrm{K}_{\mathrm{e}} \quad$ Exciter constant related to field self-excitation,

$\mathrm{K}_{\mathrm{f}} \quad$ Feedback gain of regulator stabilizer circuit,

$\mathrm{T}_{\mathrm{a}} \quad$ Regulator amplifier time constant (s),
$\mathrm{T}_{\mathrm{r}} \quad$ Input filter regulator time constant,

$\mathrm{T}_{\mathrm{e}} \quad$ Exciter time constant,

$\mathrm{T}_{\mathrm{f}}$ Time constant of the regulator circuit stabilizer (s),

$\mathrm{E}_{\max }$ Maximum output voltage of the exciter (applied to the generator field)

$\mathrm{E}_{\min } \quad$ Minimum output voltage of the exciter (applied to the generator field)

$\mathrm{V}_{\max }$ Maximum voltage regulator output (pu),

$\mathrm{V}_{\min }$ Minimum voltage regulator output (pu)

$\mathrm{E}_{\mathrm{f}} \quad$ Field voltage (pu),

$\mathrm{S}_{\mathrm{r}} \quad$ Rated apparent power,

$\mathrm{U}_{\mathrm{r}} \quad$ Rated voltage,

L Length,

$\mathrm{R}_{\mathrm{a}} \quad$ Armature resistance (pu),

$\mathrm{x}_{\mathrm{L}} \quad$ Armature leakage inductance $(\mathrm{pu})$,

$\mathrm{x}_{\mathrm{d}} \quad$ Direct axis reactance $(\mathrm{pu})$,

$\mathrm{x}_{\mathrm{q}} \quad$ Quadrature axis reactance $(\mathrm{pu})$,

$\mathrm{x}_{\mathrm{d}}^{\prime} \quad$ Direct axis transient reactance $(\mathrm{pu})$,

$\mathrm{x}_{\mathrm{q}}^{\prime} \quad$ Quadrature axis transient reactance $(\mathrm{pu})$,

$\mathrm{x}_{\mathrm{d}} \quad$ Direct axis subtransient reactance(pu),

$\mathrm{x}_{\mathrm{q}} \quad$ Quadrature axis subtransient reactance (pu),

$\mathrm{x}_{0} \quad$ Zero sequence reactance $(\mathrm{pu})$,

$\mathrm{T}_{\mathrm{d} 0}^{\prime} \quad$ Open-circuit direct axis transient time constant (s),

$\mathrm{T}_{\mathrm{q} 0}^{\prime} \quad$ Open-circuit quadrature axis transient time constant $(\mathrm{s})$,

$\mathrm{T}_{\mathrm{d} 0}$ Open-circuit direct axis subtransient time constant (s),

$\mathrm{T}{ }_{\mathrm{q} 0} \quad$ Open-circuit quadrature axis subtransient time constant (s),

$\mathrm{P} \quad$ Number of poles,

f Frequency $(\mathrm{Hz})$,

$\omega_{\mathrm{s}} \quad$ Synchronous speed $(\mathrm{rad} / \mathrm{s})$.

G Gain of flyball

$\mathrm{T}_{\mathrm{fb}} \quad$ Time constant of flyball,

$\mathrm{T}_{1} \quad$ First time constant of control system,

$\mathrm{T}_{2} \quad$ Second time constant of control system,

$\mathrm{T}_{3} \quad$ Third time constant of control system,

$\mathrm{T}_{4} \quad$ Departure time constant of water (hydraulic turbine),

$\mathrm{T}_{5} \quad$ Time constant of hydro/thermal turbine. 


\section{Introduction}

Renewable energy sources will increasingly play a more relevant participation in the global energy matrix in the coming decades. The need to increase the energy supply reliability and the growing concern about environmental and social issues and also reducing dependence on fossil fuels contribute to global interest in sustainable solutions through the generation of energy coming from clean and renewable sources. In this context, Brazil stands out due to its leadership in key negotiating fronts to increase the use of renewable sources of energy [1].

The development of these sources enters a new stage in Brazil with the implementation of the Brazilian Renewable Energy Incentive Program- PROINFA ("Programa de Incentivo as Fontes Alternativas de Energia Elétrica") established under the Ministry of Mines and Energy - MME ("Ministério de Minas e Energia") by Law $\mathrm{n}^{\circ} .10,438$, dated April 26, 2002, and revised by Law $\mathrm{n}^{\circ}$. 10,762 of November 11, 2003 [1]. This initiative aims to promote the diversification of the Brazilian Energy Matrix, increasing the share of electricity generated by projects based on wind power, biomass and small hydropower in the National Interconnected System-SIN ("Sistema Interligado Nacional") [2]. The energy generated by the projects contracted under PROINFA will be acquired and marketed by the Brazilian utility company -Eletrobras - for a period of 20 years [3].

As a result of this change, the number of distributed generators connected directly to distribution grids is growing. Therefore, simple and didactic computational tools become necessary to simulate the behaviour of the electrical system considering the inclusion of distributed generators, both in steady state as under disturbances, and also to analyse the impact of the connection of these new energy sources.

Some papers have been published on the modelling and simulation of distributed generators connected to the electrical system [4], however, in this case, the representations that have been employed are typically implemented within more extensive programs in the form of cards (codes). Due to the inherent complexity of some programs, this paper presents computational models of speed governors and voltage regulators developed in the ATPDraw environment through specific icons. Such modelling allows the user to easily change the parameters of the system components to be simulated, besides being a friendly interface. It is noteworthy that the software ATP, together with its ATPDraw interface, are a computer simulation package which enables time domain transient phenomena analyses. ATP is costless and widely used in the companies of the energy sector.

The prime mover that drives the synchronous machine is fed with steam from burning waste (pulp and peel) of sugarcane in many Brazilian industries whose main objectives are the production of sugar and alcohol. Thus, the electricity generated by the industry is used to attend the both the local load and the distribution grid. Every company working in this manner (selling energy to the utility) is referred to as an Independent Power Producer (IPP) of a distributed generation system.

Within this context, it is simulated a three-phase shortcircuit at the Point of Common Coupling (PCC) with the local power utility in order to verify aspects related to power quality and stability, since the usually related problems found in the transmission system can also occur throughout the distribution. Furthermore, it will be analysed the influence and importance of speed governor and voltage regulator during the system response to the applied contingency.

Therefore, this paper aims firstly to show the models for the synchronous machine and its associated controls which are developed and implemented in ATPDraw, the visual interface of ATP program. Secondly, the efficiency and importance of synchronous machine controls are investigated with the computer simulations here presented.

\section{System modelling}

\section{A. Synchronous Generator}

The generator of the independent producer was modelled according to the ATP model of synchronous machine referred as SM 59 type controlled. The equations used to represent the synchronous machine in ATPDraw are based in references [5],[6]. The oscillation equation that governs the movement of the machine is indicated in (1):

$$
J_{m} \frac{d^{2} \theta_{m}}{d t^{2}}+D_{m} \frac{d \theta_{m}}{d t}=T_{m}-T_{e}=T_{a}
$$

The moment of inertia of the synchronous machine at the rated speed is given by equation (2), followed by the equations of kinetic energy (3) and mechanical angular speed (4):

$$
\begin{gathered}
H=\frac{E_{c}}{S_{\text {rating }}} \\
E_{c}=\frac{1}{2} J_{m} \omega_{m}^{2} \\
\omega_{m}=\frac{d \theta_{m}}{d t}
\end{gathered}
$$

\section{B. Voltage Regulator}

The voltage regulator is based on the model recommended by IEEE, called Type I [7],[8]. Figure 1 shows the block diagram for this regulator.

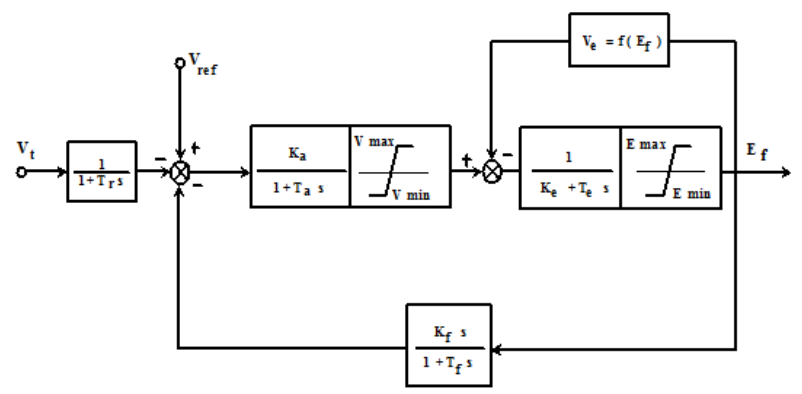

Fig. 1.Voltage Regulator block diagram: IEEE Type1model 


\section{Speed Governor}

The speed governor was implemented according to the simplest IEEE model [7],[8]. Figure 2 shows the block diagram for such control associated with a steam turbine.

For the modelling of the regulators and the synchronous generator it was used the DBM ("Data Base Module") of ATP. This function allows one to create a library of models, facilitating and improving the use of the program in various simulations.

The DBM function allows the creation of a module, comprising one or more components, for the implementation of the file being simulated. According to the mentioned parameters, specific modules were created to represent the synchronous machine, voltage regulator and speed governor. It is used the ATP programming routine called Transient Analysis of Control Systems TACS [9], which allows implementing the machine and its controls in the form of block diagrams.

Afterwards, each developed model was associated with an icon to give a visual representation of a particular component in order to be used in the ATP program through the interface ATPDraw. Thus, Figure 3 shows the icons embedded to the implemented devices.

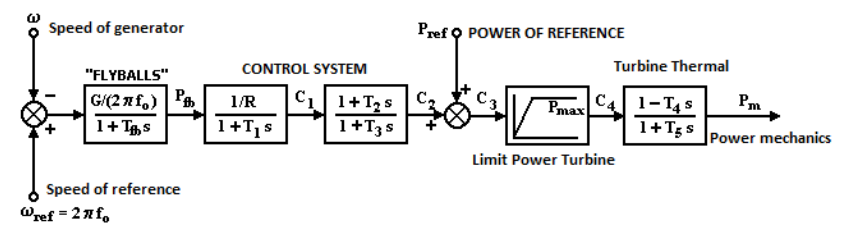

Fig. 2.Speed governor block diagram - IEEE model

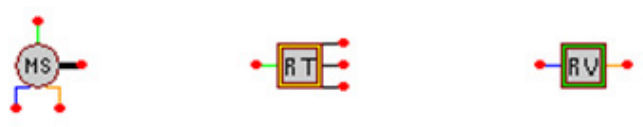

Synchronous Generator Voltage Regulator Speed Governor

Fig. 3.Icons of implemented devices

\section{Electrical System}

The electrical system used in conducting the case studies is based on the single line diagram taken from [4], which portrays a distribution system connected to the independent producer through an interconnection breaker and an isolation transformer [10], as shown in Figure 4.

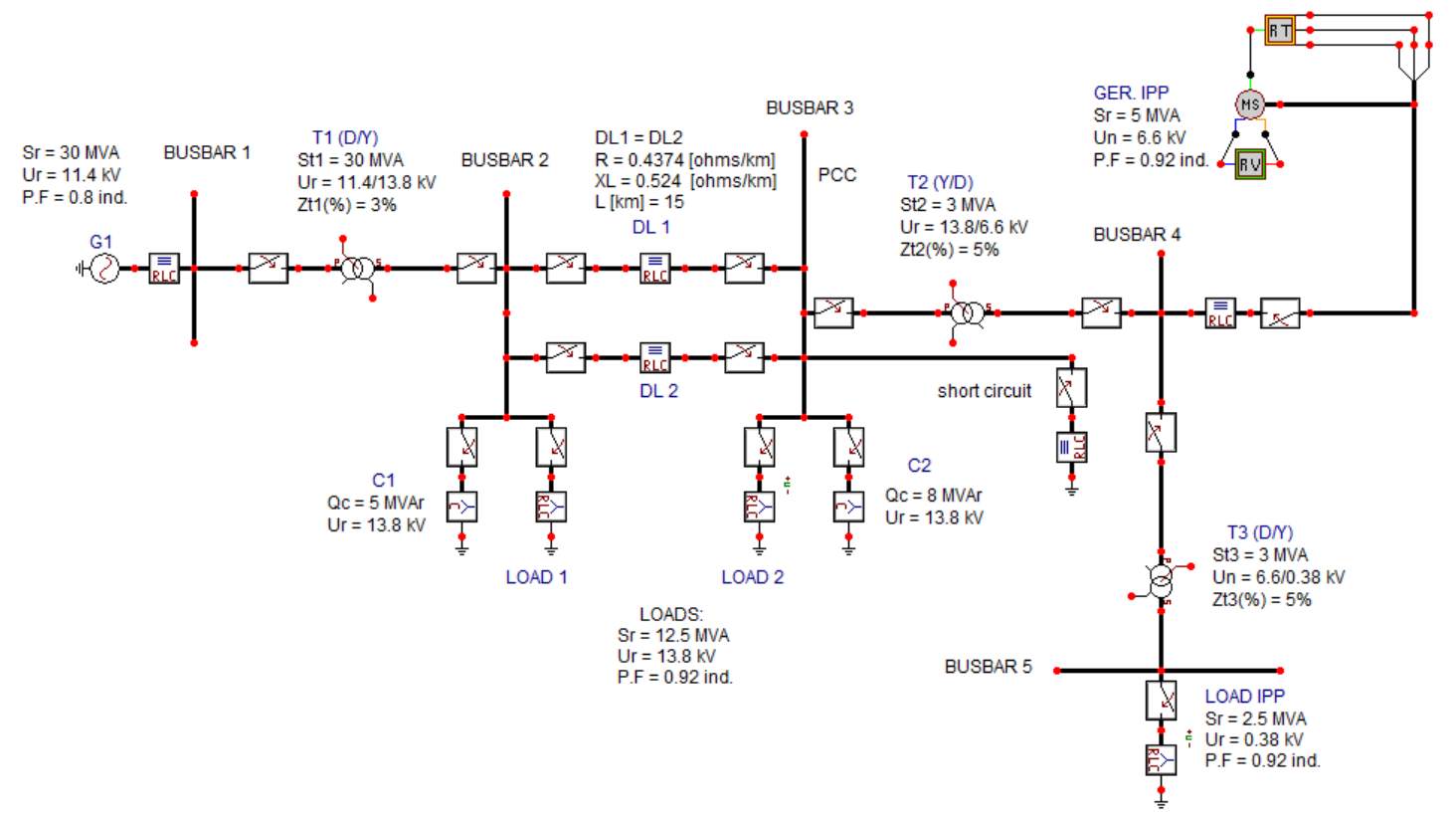

Fig. 4. Electrical system simulated by ATPDraw

Table I shows the synchronous machine parameters of the IPP generator.

Table I - Parameters of synchronous machine (IPP generator)

\begin{tabular}{|c|c|}
\hline $\mathrm{Sr}=5 \mathrm{MVA}$ & $\mathrm{X}_{0}=0.046 \mathrm{pu}$ \\
\hline $\mathrm{Un}=6.6 \mathrm{kV}$ & $\mathrm{T}^{\prime} \mathrm{d}_{0}=1.754 \mathrm{~s}$ \\
\hline $\mathrm{Ra}=0.004 \mathrm{pu}$ & $\mathrm{T}^{\prime} \mathrm{q}_{0}=0 \mathrm{~s}$ \\
\hline $\mathrm{X}_{\mathrm{L}}=0.1 \mathrm{pu}$ & $\mathrm{T}^{\prime} \mathrm{d}_{0}=0.019 \mathrm{~s}$ \\
\hline $\mathrm{X}_{\mathrm{d}}=1.8 \mathrm{pu}$ & $\mathrm{T}^{\prime}{ }^{\prime} \mathrm{q}_{0}=0.164 \mathrm{~s}$ \\
\hline $\mathrm{X}_{\mathrm{q}}=1.793 \mathrm{pu}$ & $\mathrm{H}=1 \mathrm{~s}$ \\
\hline $\mathrm{X}_{\mathrm{d}}=0.166 \mathrm{pu}$ & $\mathrm{P}=4 \mathrm{polos}$ \\
\hline $\mathrm{X}_{{ }_{\mathrm{q}}}=0.98 \mathrm{pu}$ & $\mathrm{F}=60 \mathrm{~Hz}$ \\
\hline $\mathrm{X}^{\prime}{ }_{\mathrm{d}}=0.119 \mathrm{pu}$ & $\omega_{\mathrm{S}}=188.5 \mathrm{rad} / \mathrm{s}$ \\
\hline $\mathrm{X}^{\prime}{ }_{\mathrm{q}}=0.17 \mathrm{pu}$ & \\
\hline
\end{tabular}

Table II shows the active and reactive power generated by the local power utility $\left(G_{1}\right.$ - infinite bus $)$ and the Independent Producer machine $\left(\mathrm{G}_{\mathrm{IPP}}\right)$.

Table II - Active and reactive powers generated in the system

\begin{tabular}{|c|c|c|}
\hline Source & $\mathrm{P}_{\mathrm{G}}[\mathrm{MW}]$ & $\mathrm{Q}_{\mathrm{G}}[\mathrm{MVAr}]$ \\
\hline $\mathrm{G}_{1}$ & 24.44 & 0.501 \\
\hline $\mathrm{G}_{\mathrm{IPP}}$ & 3.525 & 1.454 \\
\hline
\end{tabular}




\section{Simulations and Results}

In order to understand the influences of the expansion of distributed generation in the operation and design of systems for power distribution, the analysis proceeds to the following case study: three phase short-circuit at busbar3 - the Point of Common Coupling (PCC) between electric distribution system and the Independent Power Producer

\section{A. Case Study: Three-Phase Short-Circuit at PCC}

The study will be performed according to reference [10], whose recommendation for the occurrence of a fault in the network is that the IPP generator should be removed from the system within a maximum time of 8 cycles. Thus, it will be analysed the behaviour electric system under such disturbance.

The three phase short-circuit at busbar 3 (PCC) occurred at time $\mathrm{t}=2 \mathrm{~s}$, and it was removed from the system at time $\mathrm{t}=2.133 \mathrm{~s}$. Figure 5 shows the voltage behaviour at busbar 3. It is observed the voltage interruption during only $133 \mathrm{~ms}$ (approximately 8 cycles), a maximum period allowed for the disturbance in the system [10]. After fault removal, the voltage returns back to its pre-fault steadystate value of $1.05 \mathrm{pu}$.

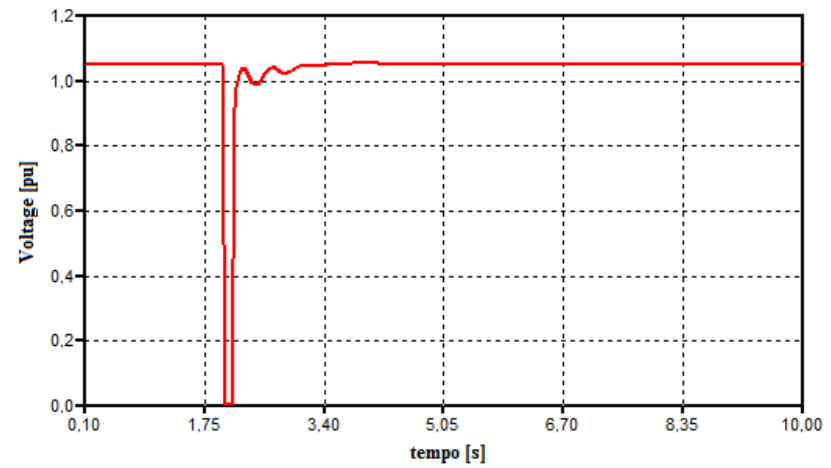

Fig. 5.Voltage at busbar 3 (PCC)

Figure 6 shows a voltage sag on busbar 4 (IPP generator), due to its proximity to the busbar 3 (PCC). The voltage value decreases reaching $0.21 \mathrm{pu}$, and, after removal of the short-circuit, it stabilizes at $1.001 \mathrm{pu}$. This fact is reflected in the quality of power experienced by the local load of Independent Producer. This result is important for some electrical loads such as computer and microprocessor based devices. If they are able to withstand this short duration voltage variation, they will be restarted due to their operating curves described by Computer Business Manufacturer Association - CBMA [11].Because of the fault the synchronous machine voltage regulator acts on the excitation field (see Figure 7) which increases its voltage so as to rise the value of the generation busbar voltage. Notice that the maximum field voltage value reached was $1.1437 \mathrm{pu}$.

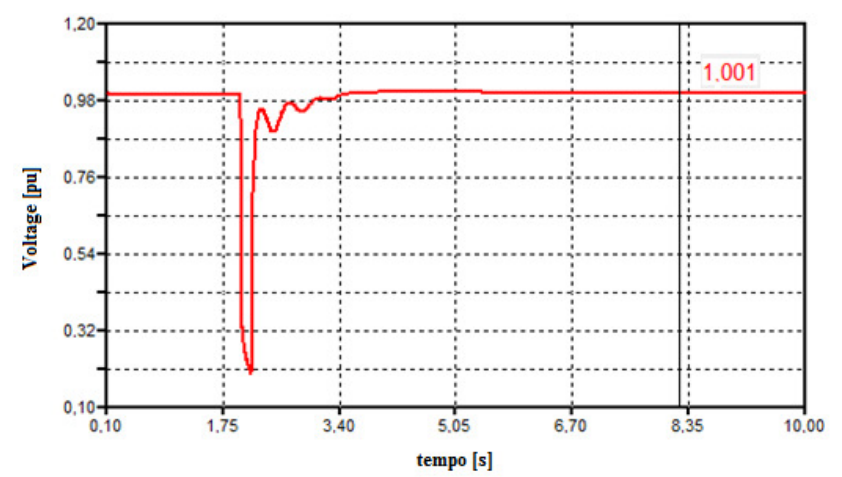

Fig. 6.Voltage at busbar 4 (IPP generator)

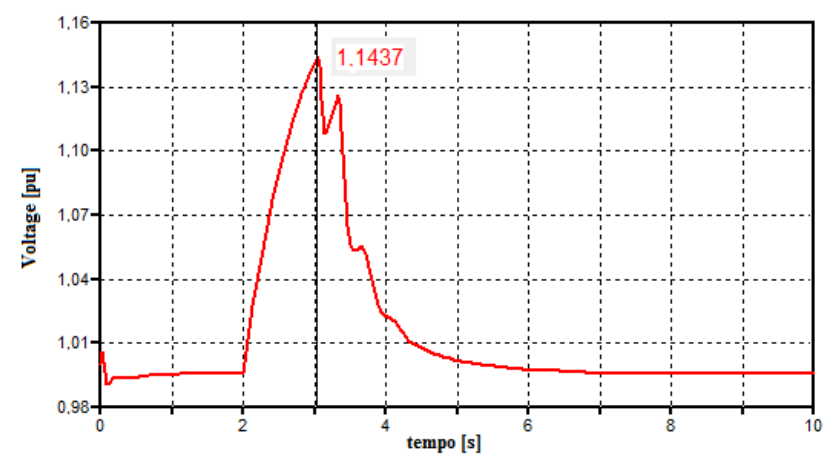

Fig. 7.IPP generator field voltage behaviour

The frequency behaviour of the IPP generator is illustrated in Figure 8. Immediately after the short-circuit, the frequency of the generator increases reaching a peak value of $60.829 \mathrm{~Hz}$. After removal of the fault, the frequency oscillates and then damps achieving $60 \mathrm{~Hz}$ at time $\mathrm{t}=3.5 \mathrm{~s}$. According to reference [10], the IPP shall provide an automatic means of disconnecting its generating equipment for over and under frequency situations. The equipment must be disconnected within 0.5 seconds for a frequency of $60.5 \mathrm{~Hz}$ and within 1.0 second for a frequency of $58.0 \mathrm{~Hz}$. No under frequency tripping shall take place between $60.0 \mathrm{~Hz}$ and $58.0 \mathrm{~Hz}$. In the case studied, Figure 8 shows that the frequency was kept above $60.5 \mathrm{~Hz}$ for only $0.088 \mathrm{~s}$ and it did not decrease below $58 \mathrm{~Hz}$. Therefore, both the under and over frequency protection will not actuate.

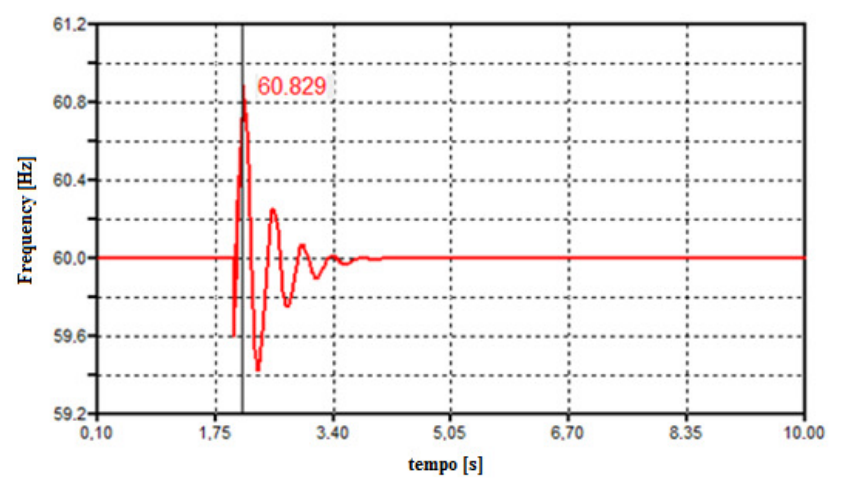

Fig. 8.Frequency at busbar4 (IPP generator)

After the applied short-circuit, the synchronous generator increases its rotation speed, reaching a peak value of $191.22 \mathrm{rad} / \mathrm{s}$, which is caused by the difference between 
the mechanical and electrical powers, as shown in Figure 9. Thus, by observation of Figure 10, it can be concluded that the machine speed governor senses it speed variation and acts in order to reduce the mechanical power used to drive the turbine-generator unit.

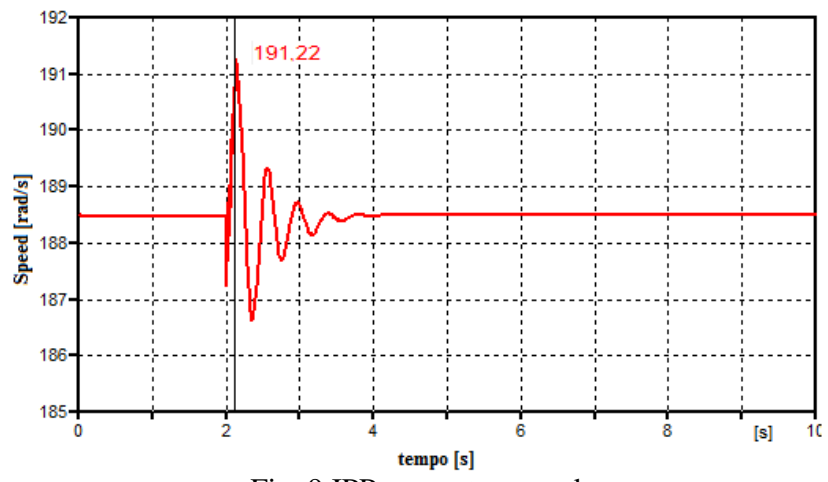

Fig. 9.IPP generator speed

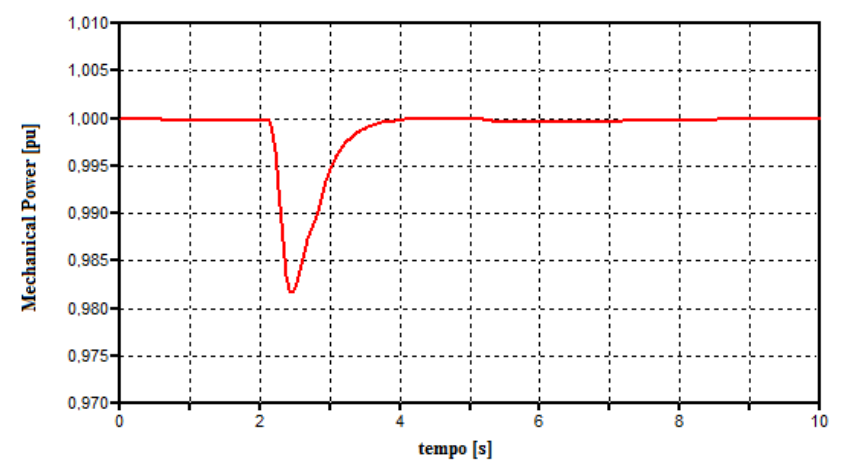

Fig. 10.Mechanical power of IPP generator

Since machine oscillations usually found in the electric power system under disturbances can also occur in the distributed generation networks, it is also important to study the stability of such reduced systems. According to reference [13], increased integration of distributed generation can significantly affect all types of stability: frequency, voltage and rotor angle. Thus, it will be investigated the rotor angle stability of IPP synchronous machine.

Immediately after the short circuit, the synchronous generator senses such disturbance due to the rise of current, as shown in Figure 11. A peak of current is observed in the early cycles of fault, mainly due to the subtransient reactance of the generator. During the short circuit period, there is a difference between mechanical and electrical power, resulting in an accelerating power (or accelerating torque) that makes the mechanical rotor speed and angle of the synchronous machine to go up [12]. Thus, the rotor angle increases as a function of this acceleration, reaching a peak value of $40.175^{\circ}$, as shown in Figure 12. With the removal of the short circuit in $2.133 \mathrm{~s}$, the rotor angle has a damped transient, and again settles into its pre-fault value, thus ensuring the system stability.

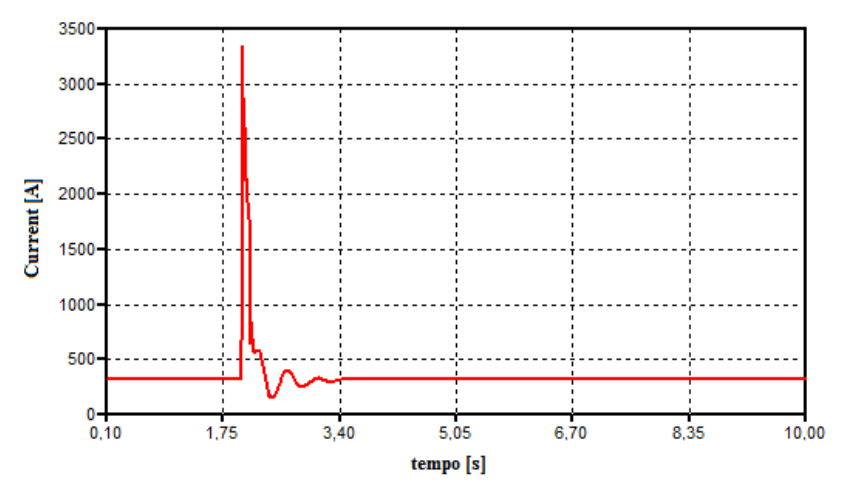

Fig. 11.IPP generator current

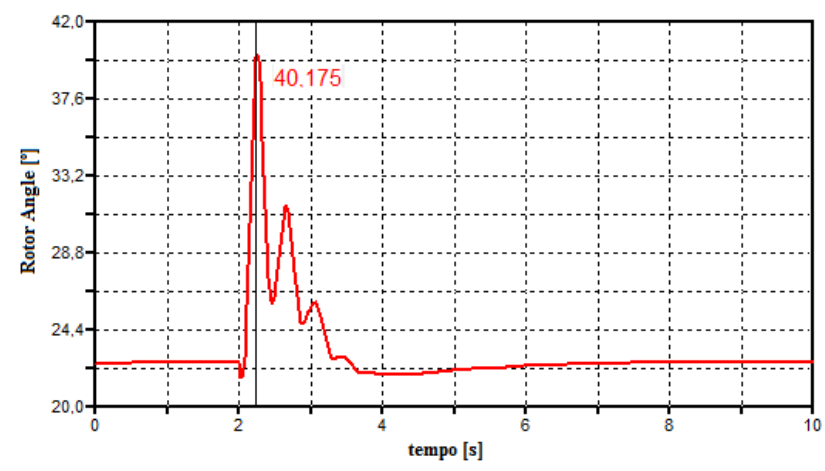

Fig. 12.Mechanical rotor angle of IPP generator

\section{Conclusions}

Due to the increase in generation energy coming from clean and renewable sources, it is extremely important to analyse the impact of the connection of these new sources of energy to the electric distribution system. Thus, this paper has contributed to computational modelling of synchronous generator and its speed governor and voltage regulator in ATP/ATPDraw program. It was presented the methodologies and procedures adopted to perform those tasks, using the TACS routine and DBM function.

All the simulated devices have now a specific icon and can be easily manipulated by computer users. The individuality of each model allows its independent use anywhere in the system. To validate these modelling it was conducted a performance analysis of the synchronous generator connected to the Independent Power Producer distribution system, and the system behaviour was analysed after a balanced three-phase fault was applied.

Such type of disturbance produced a voltage sag that could damage the electrical system equipment. It is observed a tendency of the independent producer machine to accelerate, which could lead to system instability. However, the short-circuit was applied to the system for only during $133 \mathrm{~ms}$. And after its removal, the generator was submitted to a damped oscillatory transient, maintaining system stability. The presence of the Independent Power Producer generator with voltage regulator and speed governor had a significant influence in the behaviour of the system when facing this disturbance. The machine controls acted to ensure the 
continuous supply of energy, and at the same time, respecting certain standards of quality, which basically consist in maintaining the frequency and voltage within certain limits.

Therefore, it is essential to analyse the impact that the inclusion of distributed generators can cause into the system so that it can attend consumers with an adequate standard of power quality. Therefore, it is important to emphasize that a correct and efficient modelling of this regulator and its associated speed governor also with appropriate adjustments to its controls are essential factors for the efficient and adequate operation under such a contingency that could happen in any medium voltage distribution system.

\section{Acknowledgements}

Our thanks to CAPES and FAPEMIG for the invaluable collaboration and financial support.

\section{References}

[1] Programa de Incentivo as Fontes Alternativas de Energia Elétrica - PROINFA, "Energias Renováveis no Brasil", found in 25/10/2012 at http://www.mme.gov.br/programas /proinfa/menu/programa/Energias_Renovaveis.html.

[2] Programa de Incentivo as Fontes Alternativas de Energia Elétrica - PROINFA, "O PROINFA", found in 27/10/2012, at http://www.mme.gov.br/programas/proinfa.

[3] Centrais Elétricas Brasileiras S.A. - Eletrobras, "Programas e Fundos Setoriais, PROINFA", found in 05/11/2012, at http://www.eletrobras.com/elb/data/Pages/ LUMISABB61D26PTBRIE.htm.
[4] F. A. M. Moura, Student Member, IEEE, J. R. Camacho, Senior Member, IEEE, M. L. R. Chaves and G. C. Guimarães, "Grid Integration of Renewable Sources in the Distribution Network: An Analysis Through ATP-EMTP", IEEE, PES Conference on Innovative Smart Grid Technologies (ISGT 2012), Washington-DC, USA, January 16-18, 2012.

[5] P. M. Anderson A. and A. Fouad, "Power System Control and Stability", Second Edition. Iowa, IEEE Press, A John Wiley \& Sons, Inc., Publication, 2003.

[6] P. Kundur, "Power Systems Stability and Control", McGraw-Hill, EPRI, Power Systems Engineering Series, New York, 1994.

[7] G. C. Guimarães, Dinâmica de Sistemas Elétricos - Curso - Parte I: "Modelagem de uma Máquina Síncrona e seus Controles para Estudos de Estabilidade Transitória", Universidade Federal de Uberlândia, 2009.

[8] G. C. Guimarães, "Computer Methods for Transient Stability Analysis of Isolated Power Generation Systems with Special Reference to Prime Mover and Induction Motor Modelling", PhD Thesis, University of Aberdeen, 1990.

[9] CAUE - Argentine Committee of User EMTP-ATP, Rule Book, 2001

[10] Long Island Power Authority - LIPA, "Control and Protection Requirements for Independent Power Producers, Primary Distribution Interconnections", found in 22/09/2012, at http://www.nyiso.com/public/webdocs/ services/planning/ferc_form_715/part4/lipa_interconnectio n_guide.pdf.

[11] M. H. Bollen, "Understanding Power Quality Problems: Voltage Sag and Interruptions", IEEE Press Series on Power Engineering, 2000.

[12] G. C. Guimarães, Dinâmica de Sistemas Elétricos - Curso - Parte II: "Modelagem de um Sistema Elétrico para Estudo de Estabilidade e Rejeição de Carga", Universidade Federal de Uberlândia, 2009.

[13] Gomes P., Schilling, M. T., J. W. M. "Geração Distribuída: Vantagens, Problemas e Perspectivas”. XII Seminário Nacional de Produção e Transmissão de EnergiaElétrica (SNPTEE), 1999. 